\title{
Factors Influence Students' Switching Behavior to Online Learning under COVID-19 Pandemic: A Push-Pull-Mooring Model Perspective
}

\author{
Chien-Liang $\operatorname{Lin}^{1} \cdot$ Yuan Qing $\operatorname{Jin}^{1} \cdot$ Qun Zhao ${ }^{1} \cdot \operatorname{Sung}-W e n \mathrm{Yu}^{2} \cdot \mathrm{Yu}^{\mathrm{u}}$-Sheng $\mathrm{Su}^{3}$
}

Accepted: 2 April 2021/Published online: 19 April 2021

(C) De La Salle University 2021

\begin{abstract}
Many educational institutions have adopted e-learning under COVID-19 pandemic to maintain school teaching activities. Most teachers were encouraged to use online instruction in early February 2020. Thus, whether online learning changes students' learning habits and replaces traditional physical teaching methods, online learning has become a keen topic. Based on the push-pullmooring model, we proposed a comprehensive research model and explored the impact of online learning during COVID-19 pandemic on students' attitude and behavioral intention. We found that push effects (perceived security risk, learning convenience, and service quality), pull effects (usefulness, ease of use, teacher's teaching attitude, tasktechnology fit), and mooring effects (switching cost, habit) had significantly influence the switching intentions of users from physical course to online learning platforms. The
\end{abstract}

Yu-Sheng Su

ntoucsiesu@mail.ntou.edu.tw

Chien-Liang Lin

lin.chienliang@gmail.com

Yuan Qing Jin

jinyuanqing@nbu.edu.cn

Qun Zhao

zhaoqun1981@163.com

Sung-Wen Yu

oilwarm2228@gmail.com

1 College of Science and Technology, Ningbo University, Cixi, Zhejiang, China

2 Department of Marketing and Distribution Management, National Pingtung University, Pingtung, Taiwan

3 Department of Computer Science and Engineering, National Taiwan Ocean University, Keelung, Taiwan findings of this study will bring more insights into e-learning during an epidemic crisis.

Keywords COVID-19 · Push-Pull-Mooring Model · Migration Behavior · Online Learning · PLS-SEM

\section{Introduction}

The new coronavirus has changed the mode of physical learning since early 2020. According to UNESCO (2020), as of June, schools in more than 180 countries had been closed. Nations worldwide have also responded to the devastation caused by disease and reassessed the services of online learning to face the challenges in the educational environment. The Ministry of Education of China also required schools of all levels to respond to the changes brought about by the pandemic and adjust the form of classes (Cheng, 2020; Zhang et al., 2020). They started such modes of teaching as "online new semester," "Suspending Classes without Stopping Learning," and "Suspending Classes Without Stopping Teaching." All universities are encouraged to use online teaching methods such as live broadcast teaching, video teaching, massive open online courses (MOOCs), and small private online courses (SPOCs) (Cheng, 2020). Unlike the online teaching methods that everyone is accustomed to in the past, the reason for this online teaching comes from an urgent policy. Almost all courses and teaching plans must be converted into online learning mode in a very short time. With the impact of the pandemic, students were forced to devote time and energy to familiarize themselves with the use of online teaching platforms. Increased students' intention to switch to online learning and reduce learning shocks are also key factors during the pandemic. 
Previous studies explaining students' behavior on how to use online learning mainly applied theories such as the technology acceptance model (Ashrafi et al., 2020; Huang \& Teo, 2019; Eksail \& Afari, 2019; Huang et al., 2020; Su et al., 2019a, b, 2020, 2021a, b), expectation confirmation theory (Dai et al., 2020), but most of them were used to explain the use and continuance intention of online learning platforms. This study believes that the switching intention is an important factor for students and teachers because the teaching methods from the past have been implemented for many years. If there is no strong factor to change the teaching method, the effect of learning will not be achieved. Chen and Keng (2019) investigated the switching intentions of transitioning from physical liveaction English learning to online live-action English learning platforms and suggested that online learning should pay greater attention to the needs of learners to enhance the value of students' overall learning. Liao et al. (2019) explored the switching intentions of the social network-based learning platform and pointed out the experience of online learning and the substitution of platform functions are important factors affecting the switching behavior.

How to think about switching intention from switching classrooms to online learning platforms? Additionally, regarding the switching intentions of the users, previous studies mainly used PPM to explain the switching behavior (Hou \& Shiau, 2020; Xu et al., 2014). Based on Bansal et al. (2005) pointed out, the PPM model structures a list of predictor variables into theoretically defined effect categories. Unlike other theories in the marketing or information system fields, by including fixed factors such as usefulness, confirmation, satisfaction, and continuance intention in the expectation confirmation model, the PPM framework does not mandate fixed variables for the push, pull, or mooring effects. In this emergency suspension of classes, many research conceptions did not follow the basic situations or assumptions set by other theories. By using the PPM, we only need to consider the uniqueness of the research background and then determine the push, pull, and mooring factors of different topics, which is more appropriate to explore the transfer of Chinese college students from physical courses to online learning. Previous research that used the PPM model to discuss related issues shows that the main push and pull factors are dissatisfaction (Tang \& Chen, 2020; Xu et al., 2014; Chang et al., 2014; Zhang et al., 2012; Su and $\mathrm{Wu}, 2020$ ), and alternative attractiveness, respectively (Tang \& Chen, 2020; Susanty et al., 2020; Jung et al., 2017; Su and Chen, 2020). However, switching intention is still affected by many factors (Hou \& Shiau, 2020).

In response to this online learning switching behavior, this study uses security risks and learning convenience as the main factors in the push effect, and task-technology fit, ease of use, and usefulness as the main factors in the pull effect. In terms of mooring factors, this research tries to understand the influence of habits and learners' switching costs through statistical verification to illustrate the impact of these three factors on learners' intention of the switch. To this end, this study also constructs an appropriate theoretical framework for previous literature. This study regards Chinese college students as subjects of the survey and tries to identify factors that mainly promote the transitioning of Chinese college students.

\section{Literature Review}

\section{Suspending Classes without Stopping Learning to China College Education}

During the pandemic, the Chinese government proposed "Suspending Classes Without Stopping Learning" and "School's Out, But Class's On" to guide schools, students, and teachers. The Ministry of Education issued the "Notice on Several Issues concerning Targeted Teacher Work during the Pandemic Prevention and Control", which proposed "suspending classes without stopping teaching and learning". It required education departments and schools to carry out online teaching according to local conditions. (Ministry of Education of the People's Republic of China, 2020). "Suspending Classes Without Stopping Learning" or "School's Out, But Class's On" refers to a state that although schools postpone the start of the 2020 spring semester, the education continues with the help of information technology (Zhang et al, 2020). The purpose of this policy is to "integrate national and local school teaching resources, provide rich, diverse, selectable, high-quality online resources for all students across the country, and support teachers' online teaching and student's online learning" (Ministry of Education of the People's Republic of China, 2020a), such as “open highquality online courses and virtual simulation experimental teaching resources for free", "develop online teaching organization and implementation plans", "develop online teaching quality standards", and "provide technical service support" to make educational resources accessible to the general public (Cheng, 2020).

\section{Push-Pull-Mooring Model}

The migration of population theory was originally conceived to understand the behavior of human migration (Lee, 1966; Moon, 1995) by explaining why people move from one place to another over time (Boyle and Halfacree 1998). The period of migration can be either short-term or 
long-term. Short-term migration, by definition, refers to people who work and live outside their homes for decades, then choose to return to their place of origin at the end of their work. Long-term migration, on the other hand, means that people leave their places of residence permanently and do not return (Jackson, 1986). Bogue (1959) argued that migration was the result of the interaction between push effects in origin and pull effects of the new destination. Push effects refer to the negative factors that encourage people to leave the origin (e.g., economic opportunity, natural disaster, etc.) (Stimson and Minnery, 1998). Pull factors attract people to move in, such as excellent quality education environment, political freedom, etc. (Stimson and Minnery, 1998). Moon (1995) revised the Push-Pull model to incorporate the mooring effect and proposed a new push-pull-mooring model. The migrants' decision to move from one geographical region to another is affected by factors of push, pull, and mooring effect. Mooring factors are associated with the migration behavior, which can either hinder or facilitate the decision behavior. Previous research that used PPM must consider the unique characteristics of the research background to further identify factors of push, pull, and mooring in different environmental contexts (Xu et al., 2014). PPM framework is a helpful utility model, as it can be further tested empirically according to broader online service switching contexts. For example, Balakrishnan et al. (2017) employed PPM model to explain switching from online learning to online Social media learning, finding that push (i.e., e-learning perception), pull (i.e., convenience, social influence, academic reasons, ease of use, and social networking) and mooring (i.e., barriers) factors have varying degrees of effects on switching intention. Liao et al. (2019) applied PPM to explain online learning switching between different social network-based learning, finding that push (i.e., social interaction and service quality), pull (i.e., the attractiveness of new services and social effect), and mooring (i.e., (switching costs and prior switching experience) factors have varying degrees of effects on switching intention. Chen and Keng (2019) investigated the switching intention that shifts from traditional physical English learning to online learning platforms. It is suggested that online learning should pay more attention to the needs of learners to enhance the value of overall learning. To better understand the Chinese college students switching intentions between online learning under COVID-19 Pandemic, PPM model provides a useful conceptual architecture and helps identify influencing factors of push, pull, and mooring effect.

\section{Push Effect}

In PPM framework, the push factor includes negative influences that drive users to leave existing services (Moon, 1995). Regarding the push factor, the information system switching effect usually includes negative views of the service provider, such as service failures, employee problems, or pricing strategies. All these views led to low levels of satisfaction (Jung et al., 2017). Previous literature discussed push effects involved different concepts ( $\mathrm{Li} \& \mathrm{Ku}$, 2018; Susanty et al., 2020; Tang \& Chen, 2020). However, this study considers the environmental particularity of Chinese college students' switching intentions to adopt online learning in the context of COVID-19 pandemic. Therefore, the dimensions of push effect variables in this study include learning convenience, service quality, and security risk to analyze the influence of push effect on the switching intention.

\section{Learning Convenience}

Convenience is defined as the time and effort consumers perceive when using or purchasing services (Berry et al., 2002). Compared with the shopping behavior in traditional physical stores, online shopping provides consumers with greater convenience and saves more time and search costs (Lai et al., 2012). In the Internet age, convenience means learning online through various devices in unlimited space and time to save more time and cost (Carter \& Campbell, 2012; Mangin et al., 2013; Hsu et al., 2018). Findings of previous studies show that convenience has an impact on the level of satisfaction and behavioral intention of physical store shopping and online shopping (Michaelidou and Christodoulides, 2011; Aagja et al., 2011; Wu et al., 2011). Chen and Keng (2019) suggested that learners perceive inconvenience from attending physical classes, which negatively affects the overall convenience, and thus learners switch to the Internet to improve their learning effect. Hence, this study defines the learning convenience of choosing online learning platforms due to the inconvenience of attending classes in physical classrooms. Therefore, this study holds that learning convenience is one of the important factors affecting the push effect.

\section{Service Quality}

Service quality is the result of a comparison between expectations and actual performance. Good service quality can provide companies with a comparative competitive advantage over competitors (Ladhari, 2009). For people using the information system, service quality is the transfer of internal employee support to external customer support. Service providers strive to provide more real-time, reliable, 
and value-focused services. Service quality is conceptualized as service providers providing effective services to the serviced (Wang and Lin, 2012). As the past studies on switching behavior, service quality is a very important factor that drives users to switch (Chang et al., 2017; Susanty et al., 2020; Tang \& Chen, 2020). In particular, when the service is poor, it will also drive the consumer to switch to a better platform or service (Jung et al., 2017; Liao et al., 2019). Chen and Keng (2019) discussed the learning transfer behavior of physical English and argued that service providers should effectively provide specific service measures for users in English learning places. When users perceive a decline in the service quality of English learning centers, they will also switch to online English learning platforms. Liao et al. (2019) discussed the social online learning platform switching behavior and suggested that when online learning platforms cannot provide effective and high-quality services, learners will also have the intention to migrate to other platforms. In this study, service quality is defined as the choice of online learning platforms when physical courses cannot meet the demand for learning services. Therefore, service quality is also one of the important factors of the push effect in this study.

\section{Security Risk}

Security risk refers to negative factors that cause potential consumer uncertainty about online transactions (Kim et al., 2008). Risk may cause consumers to reduce their intention to adopt e-services (Nicolaou and Mcknight, 2006). Even if it is adopted afterward, the high risk may also lead users to be unwilling to continue using the previous service (Yang and Lin, 2015). However, when a new service becomes more secure, the users may switch to such a service (Bhattacherjee and Park, 2014; Lai and Wang, 2015). According to previous studies, security risk refers to consumers' belief in potentially uncertain negative results of online transactions (Kim et al., 2008). However, in the research related to PPM, Cheng et al. (2019) held that security risk is a push, and defined security risk as "consumers perceive a high-security risk to the previously used service and switch to an alternative with a lower security risk". In this study, the security risk is defined as the safety problem of attending physical classes under the impact of the pandemic, which leads consumers to switch to an online learning platform with a lower security risk. Therefore, the safety risk is also one of the factors affecting the push effect in this study.

\section{Pull Factor}

Pull factors mainly involve influences in promoting people to move from one place to another (Lee, 1966). In the literature on marketing and information systems, the concept of pull mainly uses alternative attraction to explain the user's willingness to switch from offline to online consumer behavior (Lin \& Huang, 2014). Previous studies suggest that when consumers cannot meet their needs in physical stores, they look for alternative services (i.e., online shop platform) to replace the original service pattern (Chang et al., 2017). Therefore, this study considers that the pull effect variables which drive Chinese college students to switch to online learning in the context of COVID19 pandemic, including instructor attitude, task-technology fit, usefulness, and ease of use.

\section{Instructor Attitude}

As defined in the literature, instructor attitude is something that is perceived by a learner; this perception depends on the instructor's teaching style, provision of immediate feedback to students, and attitude toward the use of online learning platforms (Sun et al., 2008; Cheng et al., 2019; Lin et al., 2019). For students, an instructor's attitude during teaching will influence students' use of online learning (AlFraihat et al., 2020; Rodríguez-Ardura \& Meseguer-Artola, 2016). Such attitude is improved when the instructor responds to students' questions immediately (Cidral et al., 2018), reduces the learning gap, establishes and improves on learning mechanisms, formulates a series of teaching activities, provides comprehensive learning resources, and uses proper teaching methods or tools to motivate effective learning using interaction and communication (RodríguezArdura \& Meseguer-Artola, 2016). Instructor attitude in this study was defined in terms of the feedback given by the instructor and their support given to student learning. Correspondingly, instructor attitude is a crucial role in the context of online learning during COVID-19 pandemic. Thus, this study considered instructor attitude to be a pull factor.

\section{Task-Technology Fit}

Task-Technology Fit (TTF) model explain the success factors of the information system, and it believed that the success of the information system should consider whether the performance of the information system can meet the user's task needs, which is the main factor to explain the level of task performance (Goodhue and Thompson, 1995). Therefore, when the task meets the requirements, the task performance can be maximized for the users of the information system (Khan et al., 2018). In the face of the 
COVID-19, a global pandemic, the Ministry of Education of China took emergency management measures, which is also known as "suspended classes, ongoing learning" to enable schools to normally transfer learning activities to large-scale online learning mode even when schools are closed (Zhang et al., 2020). From the point of view of the pandemic, the online learning mode adopted itself as a feature of technology and the learning goal is a task under the outbreak of the pandemic. When the task fits the technology, the students' expected effect of learning online will be better (Wu \& Chen, 2017). Previous studies have also pointed out that this theory is often used to discuss how to achieve students' learning goals through online learning platforms (Isaac et al., 2019; Kissi et al., 2018; Lin \& Wang, 2012; Yu \& Yu, 2010; Zhang et al., 2019; Su et al., 2019). Lu and Yang (2014) defined TTF as the task requirements of how much technology helping users to complete courses or work. This study defines TTF as a general reference to whether the learning goal under the pandemic and the online learning platforms meet students' learning needs. Based on the above discussion, TTF is listed as a pull factor affecting this study.

\section{Perceived Usefulness and Ease of Use}

The concepts of usefulness and ease of use originate from the Technology Acceptance Model (TAM; Davis et al., 1989; Davis, 1989). Scholars applying TAM have posited that usefulness and ease of use encourage the adoption of online learning (Eksail \& Afari, 2019; Huang et al., 2020). TAM has evolved to become foundational to the field of information systems (Wang et al., 2008; Wang and Lin, 2012). Studies have defined an information system's usefulness by how much it improves one's efficiency at work, whereas its ease of use is simply how easy it is to use and operate (Davis et al., 1989; Davis, 1989). Among studies on PPM, Chen and Keng (2019), who investigated switching intention concerning English teaching platforms, reported that a user is more likely to switch to an online English teaching platform if they perceive it to be useful. Balakrishnan et al. (2017) demonstrated that students are more likely to switch to learning through social media if they perceive it to be easy to use. Furthermore, studies on online learning have revealed that students continue to use online learning platforms if they perceive them to be useful or easy to use (Chang et al., 2017; Ayele and Birhanie, 2018; Huang \& Teo, 2019). Considering these findings and our research context, we defined usefulness and ease of use as the user's perception that an online platform helps their learning and is easy to use respectively. We also adopted ease of use and usefulness as important sub-dimensions that exert a pulling effect.

\section{Mooring Effect}

Mooring factors refer to the personal and social impacts that may prompt a potential resident to leave or stay in their place of residence (Moon, 1995). According to this concept, this study defines the mooring factors of online learning as "influencing factors that encourage students to leave or stay in physical classrooms." Considering the impact of COVID-19 on college students in China and focus on switching cost in the literature when elaborating on the concept of mooring, we used the two dimensions of habit and switching cost. According to Chen and Keng (2019) and Liao et al. (2019), switching cost affects mooring in online learning environments. These dimensions were adopted as the mooring factors in this study.

\section{Switching Cost}

Most researchers identified Switching Costs as an important mooring factor (Chang et al., 2017; Cheng et al., 2019; Jung et al., 2017; Liao et al., 2019; Xu et al., 2014). For the concept of the Switching Costs, previous studies suggested that the concept of Switching Costs includes psychological, time, and money factors (Chen \& Keng, 2019; Huang et al., 2019; Chang et al., 2017). However, in different situations, the switching costs have different concepts. In Chen and Keng's research (2019), switching costs focus on learning costs during the process of switching from a traditional offline English learning environment to an online English learning environment, and that is the loss in students' learning efficiency. Therefore, this study defines the switching costs like the loss in students' learning efficiency while switching to the online learning platform under the pressure of COVID-19. To summarizing the above discussion, the switching cost is regarded as the factor affecting the mooring factor.

\section{Habit}

Habit entails inertia in being reluctant to switch to a new and better service (Kim \& Kankanhalli, 2009; Wang et al., 2019). Switcher behavior is induced when the alternative service offers a much greater benefit than the original service does (Polites \& Karahanna, 2012). Individuals who are habituated to use an online service rarely weigh the costs and benefits of using its alternatives. Habit, a human instinct, acts to ease our cognitive load in decision-making (Sun et al., 2017), which results in inertia (Chen \& Keng, 2019). This study defined habit as a student's proclivity on the preference of learning in a physical classroom or online. In the context of the pandemic, habit thus affects students' motivation to continue learning online. 
Consequently, this study considered habit to be another factor that influences mooring.

\section{Research Methodology and Hypotheses}

\section{Construct Operationalization}

The items were first translated into Chinese by two information management professors and then translated back into English by another translator with special training in English-Chinese translation. The translation into Chinese ensured that the respondents could read the items with no difficulty when the questionnaires were administered in China. One professional translator performed a backtranslation to ensure that the original translation was content accurate. The rationality of the questionnaire items was mainly examined by two associate professors and three Ph.D. students in related majors in the first place. Further, 38 students in a class were used as the pretest to test the item face validity of the questionnaire (Mokkink et al., 2010). Some professors and Ph.D. students were then invited to fill in, revise, and modify the first draft of the questionnaire so as to ensure the validity and applicability of this research. The content of the questionnaire was integrated with the content to ensure its validity. According to the above expert validity, the explanations of the related items and the sources of the scale in this study are as follows:

First, the scale used for measuring second-order constructs of the push effects in offline-to-online learning include perceived security risk, learning convenience, and quality of service. Perceived Security Risk, Learning Convenience and Quality of Service were measured using three items developed by Grewal et al. (2003), three items developed by Hu et al. (2016) and Chen and Keng (2019), and two items developed by Cheng (2012) and Chen and Keng (2019), respectively.

Second, the scale used for measuring second-order constructs of the pull effects in offline-to-online learning consist of four sub-constructs: usefulness, ease of use, instructor attitude, and task-technology fit. The variables of perceived usefulness are assessed using a two-item scale, as suggested by Gefen (2003). Perceived ease of use is measured using a three-item scale adapted from Mohammadi (2015). The teacher's teaching attitude was measured using three items developed by Rodriguez-Ardura and Meseguer-Artola (2016). Task-technology fit was further measured by four items developed by Isaac et al. (2019). Switching cost is measured by using a three-item scale adapted from Chen and Keng (2019). Habit is assessed with a three-item scale proposed by Chen and Keng (2019). Items of construction were revised based on the items related to switching from the physical classroom environment to the online learning environment. The research situation is consistent with this study. Finally, measures of switching intentions were adapted from $\mathrm{Li}$ and Cheng (2014) and Chen and Keng (2019).

\section{Data Collection}

The respondents in the research indicated their intention to participate in this study and completed the questionnaire voluntarily. All the respondents were anonymous and agreed to participate in the survey of this study in order to collect data. The survey was conducted in Chinese. When conducting the online survey, we explained the confidentiality of the survey process. None of the questions involved confidential information, and individual respondents completed the survey anonymously. Therefore, all the respondents were voluntary and their personal information and opinions were confidential and did not relate to any sensitive issues (Fatima et al., 2020).

The questionnaire of this study was posted on a survey website, WJX (https://www.wjx.cn/), which is a professional online survey service in China. The survey, conducted between May and June 2020, focused on Chinese universities that adopted full online learning during the COVID-19 pandemic. To ensure the validity of the questionnaires collected, we confirmed whether the students who answered the questionnaires had attended classes using online learning for 9 weeks or longer during the pandemic. Furthermore, to ensure the reliability of the questionnaires, we employed convenience sampling and snowball sampling and collected the samples by sharing the questionnaires with teachers from other universities and with our university colleagues in WeChat groups, who then distributed the questionnaires to the students in their courses. The questionnaires were answered by the students voluntarily and then collected. To encourage participation and improve response, a nominal incentive of $3 \mathrm{RMB}$ was offered to every respondent who provided complete answers.

Considering that the respondents did not understand the intention and perception of switching from offline to online courses, a simple question was designed and placed at the beginning of the questionnaire to help respondents review their switching behavior during the pandemic. A total of 870 questionnaires answered by the students of 18 universities in eight provinces were collected through WJX.

To ensure the rationality of the questionnaire collection in this study, four indicators are used as the basis for screening, which reflects the appropriateness and rationality of the questionnaire collection proposed in previous literature (Lindell \& Whitney, 2001; Hsu et al., 2018; Wu et al., 2017; Cheng et al., 2019). Among the four indicators, 
the time spent to complete the questionnaire was considered the benchmark. Filling in similar answers was also considered the reference for deletion (Cheng et al., 2019; Wu et al., 2017). Second, reverse-scored questions and an IP check were included following Lindell and Whitney (2001), Hsu et al. (2018), and Cheng et al. (2019). Finally, based on the criteria of the above literature, the standard screening mechanisms for valid questionnaires in this study are as follows: (1) The questionnaire in this study took approximately $8-15 \mathrm{~min}$ to complete. A questionnaire completed within $3 \mathrm{~min}$ indicated that the participant irresponsibly completed the questionnaire; a previous study suggested that these questionnaires be considered invalid; (2) questionnaires with the same answers (only "1" or "7" selected) or those with answers consisting of extreme values; (3) WJX (https://www.wjx.cn/) recorded and checked all IP addresses and excluded duplicate values; (4) a reverse question was added to the questionnaire as a discriminating mechanism to eliminate respondents who answered the questionnaire randomly. Finally, after excluding 16 invalid questionnaires, we collected 854 valid questionnaires for data analysis.

Of all the respondents, 238 are male (27.87 percent) and 616 are female (72.13 percent). The majority of respondents are graded between the first year and second year (79.28 percent). Before the outbreak of COVID-19 pandemic, 57.49 percent of students had reported having zero experience of online learning, and the rest (42.51 percent) has more than six months of experience. Certainly, many students with no online learning experience are because the school did not offer online courses, students did not choose online courses, or school did not offer online courses that students interested in (e.g., programming, graphic design, and arts) because these courses were too specialized. For the type of the colleges, 546 (63.93\%) colleges/universities are from government-funded colleges/universities and 308 $(36.07 \%)$ colleges/universities are from personal-funded colleges/universities. Additionally, nearly 46.25 percent of the respondents spend below one hour per day on online learning, while 14.87 percent spend over four hours. Second, in terms of the year of study, the response rates of freshmen, sophomores, juniors, and seniors were respectively $46.32 \%, 33.02 \%, 18.79 \%$, and $1.87 \%$. Fewer seniors responded because they were interning outside campus in the second semester of the fourth year of college, during which our survey was conducted. Thus, few seniors' students were in an online course.

Finally, about the college subjects of the students who filled in the questionnaire, $77(9.02 \%)$ from the law school, $82(9.6 \%)$ from the science school, $96(11.24 \%)$ from the engineering school, $113(13.23 \%)$ from the education school, 114 (13.35\%) from the humanities school and 372 $(43.56 \%)$ students belong to the commerce school. Finally, about college subjects of students who filled in the questionnaire, $77(9.02 \%)$ students are from law school, 82 $(9.6 \%)$ students are from science school, 96 (11.24\%) students are from engineering school, $113(13.23 \%)$ students are from education school, 114 (13.35\%) students are from humanities school and $372(43.56 \%)$ students belong to commerce school. The respondents tended to be women rather than men because participation in the survey was voluntary and because most respondents studied business or education, in which women are overrepresented. Studies have suggested that behavioral intention toward information system use is affected by personal factors, such as sex, age, and previous usage experience (Gefen et al., 2003; Chen et al., 2020). Thus, we took the previous experience of using online learning, college major, year of study, and sex as the control variables in our analysis of switching intentions.

\section{Research Methodology}

Based on the literature of the previous PPM framework, this study defines the individual orientation of the Push, Pull and Mooring factors according to the situation of online learning environment. Figure 1 shows the main framework and assumptions of this study. The framework is presented as follows.

\section{Hypotheses}

\section{Push Effect}

Push effect includes negative influences that drive users to leave existing services. Moreover, several studies have demonstrated the influence of push effects in switching to a new service (Hou \& Shiau, 2020; Jung et al., 2017; Li \& $\mathrm{Ku}, 2018$ ). Learning convenience, quality of service, and security risk have proven to be push-oriented effects in previous studies (Chen \& Keng, 2019; Cheng et al., 2019; Liao et al., 2019). In general, learning convenience, quality of service, and security risks are push factors. Therefore, the following hypothesis was formulated:

H1 The higher the learning convenience, quality of service, and perceived security risk of offline learning services, the lower the likelihood that the student will have offline-to-online learning switching intentions.

\section{Pull Effect}

Pull effect is the factor that drives switching intention, which is produced when the provided platforms or services are more satisfactory (Tang \& Chen, 2020; Xu et al., 2014). Similarly, from the perspective of service, more 


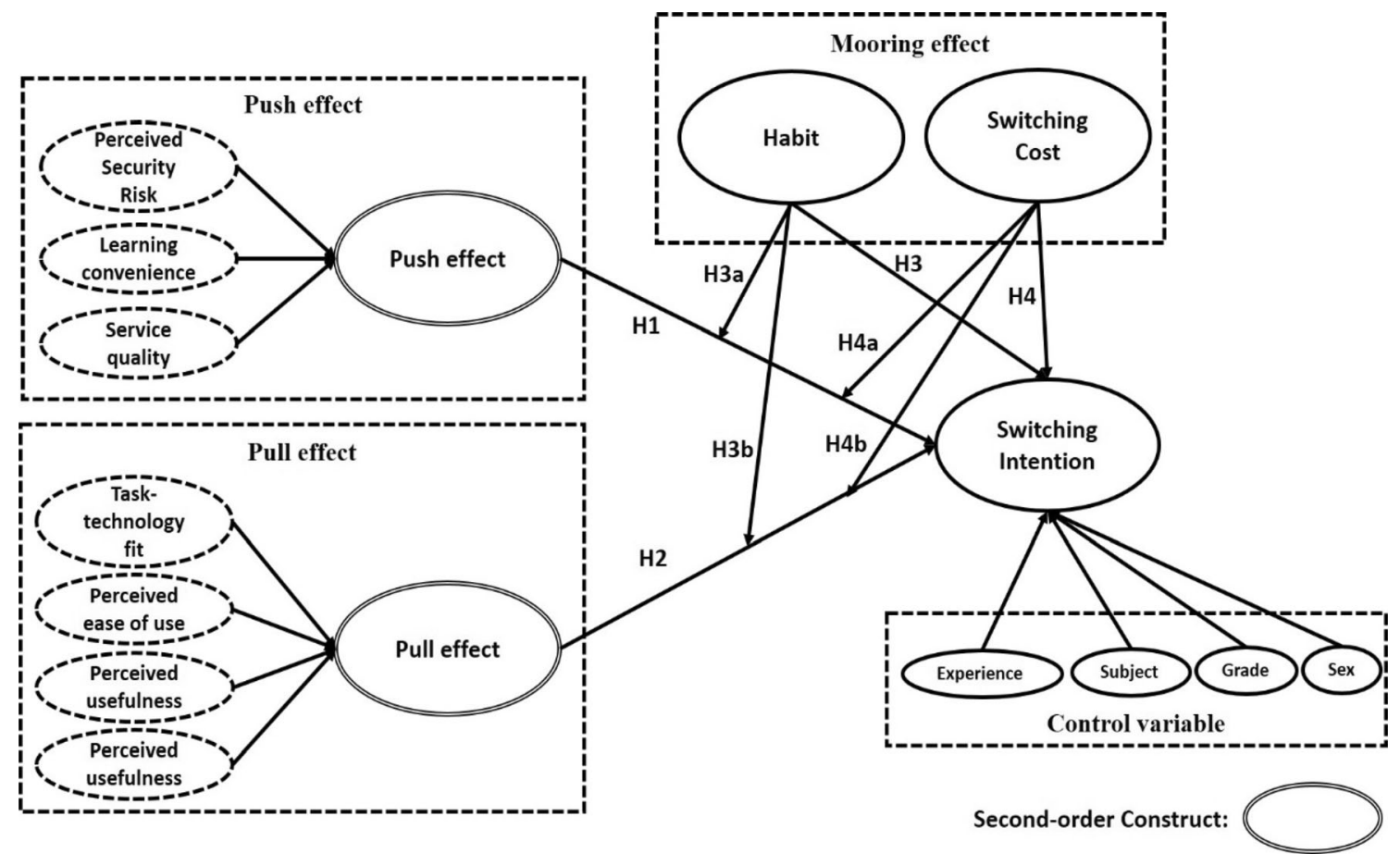

Fig. 1 Research framework

satisfactory service quality leads to a stronger pull effect that urges consumers to switch to a new service (Keaveney, 1995). The same applies to economic rationality: when a competing service provider offers positive features that are superior to the original service provider, consumers will be encouraged to switch to the better supplier. To summarize previous literature, the main factors that influence pull effect include usefulness, ease of use, task-technology fit, and instructor attitude. Therefore, the following hypothesis was formulated:

H2 The higher the perceived ease of use, task-technology fit, instructor attitude, and perceived usefulness, the higher the likelihood that the user will have offline-to-online learning platform switching intentions.

\section{Habit}

Habit is a behavioral pattern produced by past habits among consumers (Li, 2018). Thus, regardless of the presence options, previous habits prompt consumers to stay with their current service providers. Furthermore, despite the availability of numerous other service plans, consumers are often unwilling to change (Kuo et al. 2013). However, habit directly affects switching intention in PPM framework. Research on the internet service applications also suggests that users remain unwilling to use new services despite their relative advantages, meaning that previous used habits negatively influence switching intentions
(Cheng et al. 2019). Additionally, previous studies also indicate that mooring can weaken the relationship between push and pull effect in switching intentions (Chen \& Keng, 2019; Wang et al., 2019). Previous used habits make students prone to maintaining the status quo, so it contribute to a relative low motivation to switch from physical course to online learning. Therefore, we assume that previous used habits affect the relationship between the push and pull effect of students using online learning and their switching intention, we propose the following hypotheses.

H3 The higher the physical course learning habit, the lower the likelihood that the student will intend to switch from an offline to online learning platforms.

H3a The stronger the previous habits of use, the weaker the relationship between push effect and switching intentions.

H3b The stronger the previous habits of use, the weaker the relationship between pull effect and switching intentions.

\section{Switching Cost}

Liao et al. (2019) indicated that high switching cost hinders switching intention, which reflects the phenomenon of customer migration between products and services in the market. Hence, currently, free online learning platforms can still cultivate customers' loyalty by leveraging 
nonfinancial switching costs. Furthermore, the literature review revealed the impact of switching costs on user's switching intentions (Chang et al., 2017; Jung et al., 2017; Xu et al., 2014). However, according to PPM framework, mooring effects directly affect switching intention. Studies have also demonstrated that mooring effects reduce the influence of push and pull effect on switching intention (Chen \& Keng, 2019; Wang et al., 2019). If a student feels higher efficiency in traditional physical course learning than in online learning, the student is less likely to have the switching intention. Therefore, low switching costs will also improve the switching intention of students. Besides, we posited that the push and pull effect of switching costs being generated by students' use of online learning platforms would have a weak influence on switching intention. Therefore, this study proposes the following hypothesis.

H4 The higher the physical course learning of Switching Costs, the lower likelihood of student will have an offlineto-online learning platform switching intention.

H4a The stronger the switching cost, the weaker the relationship between push effect and switching intentions.

H4b The stronger the switching cost, the weaker the relationship between the pull effect and switching intentions.

\section{Results}

In this study, the research model was evaluated using partial least squares (PLS). The main reasons were that the research uses PLS-SEM in exploratory research for theory development and that the research requires latent variable scores for subsequent analysis (Gefen et al. 2011; Shiau \& Chau, 2016; Shiau et al. 2019). Furthermore, this research model employs a second-order model with the reflectiveformative type (Becker et al., 2012). In addition, Straub et al. (2004) pointed out content validity assesses whether the researcher has chosen measures that appropriately capture the full domain of the construct. When specifying a construct that is either formative or reflective, it is critical that the entire domain of the construct is captured. Given that formative constructs are defined by the dimensions or measures that form them, it is absolutely imperative to establish content validity. Without a full and complete definition of a formative construct, important aspects can be left out, and this will result in a misspecification of the construct (Petter et al., 2007). In this study, push effect and pull effect were defined as a second-order formative construct, Among Push effect construct including three reflective dimensions-Perceived security risk, Learning convenience, and Service quality. Pull effect construct including four reflective dimensions - Perceived ease of use, Perceived usefulness, Task-technology fit, and Instructor attitude. However, to test a second-order formative model, PLS-SEM is the appropriate choice because Covariance-based SEM (e.g., AMOS) is not able to test the second-order formative model (Huang \& Shiau, 2017). Therefore, the PLS approach is appropriate for this research model analysis.

As for multicollinearity, according to the literature suggestion by Hair et al. (2017), Hair et al. (2017)), value tolerance has a threshold of 0.10 and a VIF value below 5 . Table 1 presents all construct VIF values range from 1.701 to 4.453 , which shows that the results of this study meet the requirements.

\section{Measurement Model}

The measurement model is used to examine reliability, convergent validity, and discriminant validity (Shiau \& Chau, 2016; Shiau et al., 2020a, 2020b). Internal consistency can be assured by examining the composite reliability of the constructs (Fornell \& Larcker, 1981). As shown in Fig. 2, Cronbach's $\alpha$ value for all constructs was well above the recommended threshold of 0.70 (Hair et al., 2006) and ranged from 0.877 (SwCo) to 0.956 (TTF). Composite reliability (CR) value greater than 0.7 , and ranged from 0.924 (SwCo) to 0.968 (TTF) (Hair, Babin et al., 2017; Hair, Hollingsworth et al., 2017). roh_A value for each construct was well above the recommended threshold of 0.7 (Dijkstra \& Henseler, 2015), and obtained values ranging from 0.881 ( $\mathrm{SwCo}$ ) to 0.956 (TTF). The results indicated that our measurement model had good internal consistency.

Convergent validity can be evaluated by checking whether the average variance extracted (AVE) values are larger than 0.5 (Fornell \& Larcker, 1981), and ranged from 0.802 (SwCo) to 0.940 (SQ). All of the Factor loading of all items are significant and greater than 0.7 (Hair, Babin et al., 2017; Hair, Hollingsworth et al., 2017). Therefore, the convergent validity of these measures is satisfied, as shown in Table 1.

The discriminant validity of the constructs was evaluated using the approaches evaluated by Fornell-Larcker (1981) method. The all square roots of the AVE values are higher than all the correlation coefficients shown, which again indicates the appropriate discriminant validity of these measures (Fornell \& Larcker, 1981), as shown in Table 2. The result indicated that our measurement model had acceptable discriminant validity.

In Table 3, the formative measures of second-order constructs were assessed based on the significance $(p<0.05)$ of their weights, which indicated their contributions to the corresponding second-order constructs 
Table 1 Analysis results of Factor loading, Cronbach's $\alpha$, roh_A, composite reliability and AVE

\begin{tabular}{|c|c|c|c|c|c|c|}
\hline Construct & Factor Loading & $\alpha$ & roh_A & $\mathrm{CR}$ & AVE & VIF \\
\hline Perceived security risk (SER) & $\begin{array}{l}0.961 * * * \\
0.954 * * * \\
0.938 * * *\end{array}$ & 0.947 & 0.947 & 0.966 & 0.904 & 1.638 \\
\hline Learning convenience (LC) & $\begin{array}{l}0.887 * * * \\
0.934 * * * \\
0.935 * * *\end{array}$ & 0.908 & 0.911 & 0.942 & 0.845 & 1.956 \\
\hline Service quality (SQ) & $\begin{array}{l}0.970 * * * \\
0.969 * * *\end{array}$ & 0.936 & 0.936 & 0.969 & 0.940 & 1.701 \\
\hline Habit (HABIT) & $\begin{array}{l}0.932 * * * \\
0.947 * * * \\
0.907 * * *\end{array}$ & 0.921 & 0.921 & 0.950 & 0.863 & 2.111 \\
\hline Perceived ease of use (EOU) & $\begin{array}{l}0.921 * * * \\
0.947 * * * \\
0.959 * * *\end{array}$ & 0.937 & 0.938 & 0.960 & 0.888 & 2.594 \\
\hline Perceived usefulness (PU) & $\begin{array}{l}0.964 * * * \\
0.966 * * *\end{array}$ & 0.926 & 0.927 & 0.964 & 0.931 & 3.774 \\
\hline Task-technology Fit (TTF) & $\begin{array}{l}0.940 * * * \\
0.959 * * * \\
0.947 * * * \\
0.914 * * *\end{array}$ & 0.956 & 0.956 & 0.968 & 0.883 & 4.453 \\
\hline Instructor attitude (IAT) & $\begin{array}{l}0.926 * * * \\
0.925 * * * \\
0.938 * * *\end{array}$ & 0.922 & 0.924 & 0.950 & 0.922 & 2.456 \\
\hline Switching cost (SwCo) & $\begin{array}{l}0.899 * * * \\
0.904 * * * \\
0.883 * * *\end{array}$ & 0.877 & 0.881 & 0.924 & 0.802 & 2.497 \\
\hline Switching intention (SwInt) & $\begin{array}{l}0.925 * * * \\
0.941 * * * \\
0.904 * * * \\
0.922 * * *\end{array}$ & 0.942 & 0.943 & 0.958 & 0.852 & DV \\
\hline
\end{tabular}

CR (Composite reliability); VIF (Variance inflation factor); DV (Dependent variable); AVE (Average variance extracted)

***Significant at $p<0.01$

(Wang \& Haggerty, 2011). As shown in Table 3, the three dimensions of Push effect (Perceived security risk, Learning convenience, and Service quality) and the four dimensions of Pull effect (Perceived usefulness, Perceived ease of use, Instructor attitude, Task-technology fit) significantly contributed to their constructs in this context. Thus, we found support for the dimensions of the Push and Pull effect as theorized and tested within our sample.

\section{Structural Model}

To test our hypotheses, a bootstrap techniques resampling procedure was used to examine the stability of the PLS estimates, using resamples of 5000 (Hair, Babin et al., 2017; Hair, Hollingsworth et al., 2017). Figure 2 shows the results. Overall, the research model is explained 64.7 percent of the variance in Switching Intention to adopt online learning. These results show that the proposed research model has a rather high explanatory power and provides substantial support for $\mathrm{H} 1$ through $\mathrm{H} 4 \mathrm{~b}$.

The empirical results support the hypotheses $\mathrm{H} 1$ to $\mathrm{H} 4$. Push effect (H1) has a negative significant influence switching on intention $(\beta=-0.303, \mathrm{t}$-value $=5.622$, $\mathrm{p}<0.05)$, the results are consistent with those of Chen and Keng (2019) and Cheng et al. (2019). Overall, the results of the push effect, which influenced college student behavior in leaving the physical courses and switching to online learning, revealed that the inconvenience and inadequate service quality of physical courses, as well as security 


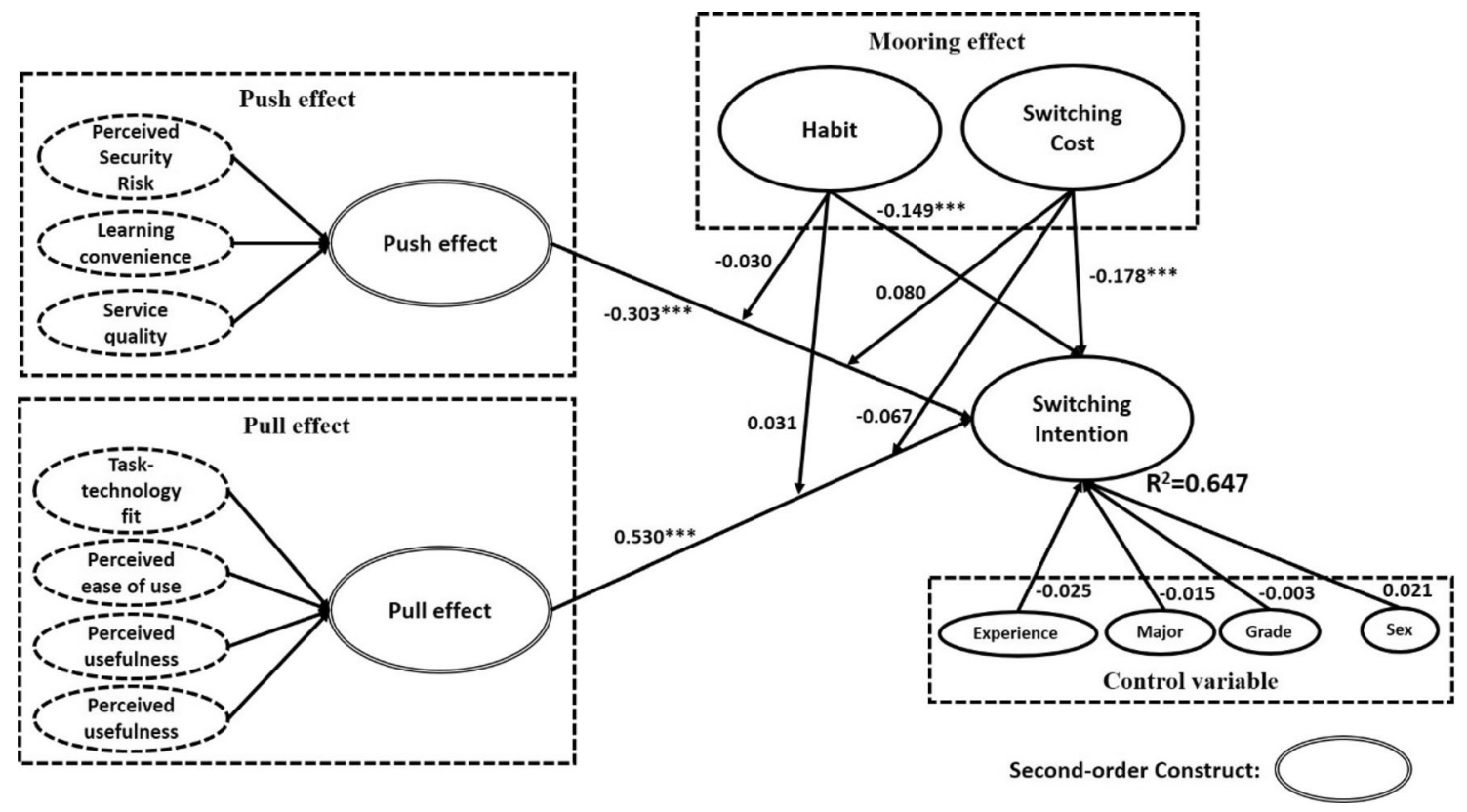

Fig. 2 PLS results of the research model

Table 2 Analysis results of discriminant validity (Fornell-Larcker Criterion)

\begin{tabular}{|c|c|c|c|c|c|c|c|c|c|c|}
\hline & Habit & TTF & LC & SER & IAT & EOU & PU & SQ & SwInt & SwCo \\
\hline Habit & 0.929 & & & & & & & & & \\
\hline TTF & 0.526 & 0.940 & & & & & & & & \\
\hline LC & -0.606 & -0.669 & 0.919 & & & & & & & \\
\hline SER & -0.435 & -0.461 & 0.597 & 0.951 & & & & & & \\
\hline IAT & 0.620 & 0.720 & -0.569 & -0.29 & 0.930 & & & & & \\
\hline EOU & 0.437 & 0.720 & -0.599 & -0.401 & 0.707 & 0.943 & & & & \\
\hline PU & 0.462 & 0.847 & -0.648 & -0.483 & 0.644 & 0.702 & 0.965 & & & \\
\hline SQ & -0.768 & -0.620 & 0.617 & 0.511 & -0.666 & -0.528 & -0.561 & 0.969 & & \\
\hline SwInt & 0.478 & 0.761 & -0.657 & -0.561 & 0.562 & 0.601 & 0.730 & -0.582 & 0.923 & \\
\hline SwCo & -0.644 & -0.496 & 0.568 & 0.645 & -0.477 & -0.407 & -0.489 & 0.730 & -0.589 & 0.896 \\
\hline
\end{tabular}

Perceived security risk (SER); Learning convenience (LC); Service quality (SQ); Habit; Perceived ease of use (EOU); Perceived usefulness (PU); Task-technology Fit (TTF); Instructor attitude (IAT); Switching intention (SwInt), Switching cost (SwCo)

Table 3 Analysis results of weights

\begin{tabular}{llr}
\hline Construct & Sub-construct & Weights \\
\hline Push factors & Perceived security risk (SER) & $0.438 * * *$ \\
& Learning convenience (LC) & $0.444 * * *$ \\
& Service quality (SQ) & $0.293 * * *$ \\
Pull factors & Perceived ease of use (EOU) & $0.265^{* * *}$ \\
& Perceived usefulness (PU) & $0.202^{* * *}$ \\
& Task-technology Fit (TTF) & $0.402 * * *$ \\
& Instructor attitude (IAT) & $0.247 * *$ \\
\hline
\end{tabular}

$* * * p<0.01$ 
considerations during the pandemic, were all essential push effects leading to online learning.

Second, the pull effect $(\beta=0.530, \mathrm{t}$-value $=12.429$, $\mathrm{p}<0.05$ ) has a positive significant influence on switching intention, thus, supporting H2. Pull effect affected student switching intention to online learning during the pandemic, an observation that was consistent with the results of previous discussions on switching intention to online learning (Balakrishnan et al., 2017; Cheng et al., 2019). Thus, the effects of pull factors on switching intention strengthened the function and operability of the overall online learning system, improved lecturer attitudes, and enable curriculum content to be more in line with the student needs, thereby attracting students to switch to online learning. These aspects constituted the crucial concepts of online learning pull effects. We also found Habit $(\beta=--0.149$, $\mathrm{t}$-value $=3.759, \mathrm{p}<0.05)$ strong negative influence continuance intention, as posited in $\mathrm{H} 3$. As anticipated, that is consistent with the results of past studies (Hsieh et al., 2012; Cheng et al., 2019). The results of the present study demonstrated that previous use habits did not change with user switching intention, indicating that despite the numerous advantages of physical course over online learning (e.g., more satisfactory interaction, face-to-face communication), students were still reluctant to return to physical courses due to the pandemic. Consequently, despite their previous use habits, students still chose to accelerate their switch to online learning services in a learning environment shaped by emergency management during the COVID-19 pandemic. Switching cost $(\beta=-0.178, \mathrm{t}$-value $=3.677, \mathrm{p}<0.05)$ had a negative impact on switching intention. Thus, $\mathrm{H} 4$ was supported. As expected, the influence of switching costs generated by the transfer of physical courses to online learning was negative, which corresponded with the results of relevant literature (Cheng et al., 2019). To university students, using online learning platforms during the pandemic was low cost; therefore, they exhibited high switching intention. During the post-pandemic period, universities in China should encourage teachers to design courses according to the characteristics of the localities of their universities and reduce the learning costs required for online learning and the time needed to adopt online learning platforms.

According to the moderating results, $\mathrm{H} 3 \mathrm{a}$ and $\mathrm{H} 3 \mathrm{~b}$ concern the moderating effects of habit on the relationship between the Push effect and Pull effect on switching intention. Besides, the results reveal that the moderating of the mooring effect on the push effect $(\beta=--0.030$, $\mathrm{t}$-value $=1.629, \mathrm{p}>0.05)$, as well as that on the pull effect $(\beta=0.031, \quad \mathrm{t}$-value $=1.745, \quad \mathrm{p}>0.05) \quad$ on switching intentions, has no significant influence. Therefore, the results do not support $\mathrm{H} 3 \mathrm{a}$ and $\mathrm{H} 3 \mathrm{~b}$. Therefore, habit acted as a moderating effect that interfered with the effects of push and pull factors on switching intention. The results indicated that the influence of habit was non-significant, which differed from previous findings (Jung et al., 2017; Li $\& \mathrm{Ku}, 2018)$. This suggested that previous use habits did not moderate the push or pull effects on switching intention.

However, the findings showed that switching cost didn't have a moderating role in the relationship of push effect and pull effect with switching intention. Thus, $\mathrm{H} 4 \mathrm{a}$ and $4 \mathrm{~b}$ were supported. The results regarding $\mathrm{H} 4 \mathrm{a}$ and $\mathrm{H} 4 \mathrm{~b}$ are not also consistent with those previously reported (Chen and Keng, 2019; Chang et al., 2014), therefore, switching costs haven't a moderating impact on the push effect and pull effect. Finally, regarding control variables, we find previous learning experience, grade, major, and gender does not have a significant effect on switching intention, as shown in Fig. 2.

\section{Conclusion and Implication}

This research mainly discusses the switching intention from physics learning to online learning in the context of the pandemic. Although relevant literature in the past has pointed out that online learning is a future trend (Shih et al., 2008; Smith \& Ferguson, 2004), but it is the first time that learning methods have been converted into a large scale due to the pandemic. From the verification of H1, we can find that learning convenience, security risk, and service quality have negative and significant impacts on the switching intention. That is to say that if the above-mentioned levels are maintained, the intention of students to switch will not increase. The results indicate that a good, stable, and high-quality learning environment is the most important thing in push factors. If online teaching can provide a better environment, students will have a higher intention to use online learning. Moreover, the service mechanism of online learning should also be improved, such as establishing effective management and control measures for emergency curriculum establishment, providing online consultation for students, and increasing the online face-to-face teaching time. Because conventional online learning is still mainly implemented by teachers through uploading videos for students to watch online, this may lead to problems such as fatigue and inattention among students in long run.

According to the results regarding pull factors (H2), the usefulness of the platform content and difficulty in operating the platform are important indicators for future university units and teachers' choice of teaching materials and platforms. In particular, in the response of COVID-19 pandemic, the Ministry of Education of the People's Republic of China adopted the approach of suspending 
classes without stopping learning, enabling students to take online courses at home (Cheng, 2020; Yao et al., 2020). However, due to the time shortages, many teachers in China could initially use only existing online teaching platforms (MOOC platforms such as icourses, chaoxing, and zhihuishu) for teaching (Zhang et al., 2020). Thus, if the functions of online learning platforms can be enhanced and more customizing teaching materials can be provided after the pandemic, more satisfactory content and functions can be used to improve and attract students to use online learning. For example, when universities offer relevant courses, teachers may record the course content and incorporate regional case studies as supplementary materials, enabling student learning to better address local needs. Alternatively, more online face-to-face real-time interactive teaching measures can be provided to encourage students to interact with teachers in real-time through online learning and give feedback on course content. Additionally, the learning tasks generated during the pandemic and resulted in a change in the learning model. Therefore, the improvement of learners' adaptability remains to focus on teacher or university choice of curriculum platforms and the matching of teaching materials. When a curriculum design meets student needs, their learning tasks can be improved, in turn, heightening students to switch intention to online learning. Finally, the pandemic presents both a challenge and an opportunity for teachers: preparing teaching materials and improving communication and interaction with students can improve the advantages of online learning as well as student learning motivation.

Finally, concerning the concept of mooring, because previous use habits (H3) have a negative impact on student switching intention (Chen \& Keng, 2019), schools must invest more effort in their promotion of online learning during the pandemic, enabling students to realize the possible impact of the pandemic on physical classroom courses. And the influence of switching costs (H4) generated by the transfer of physical classrooms to e-learning platforms was negative, which corresponded with the results of relevant literature (Cheng et al., 2019) as expected. During the post-pandemic period, universities in China should encourage teachers to design courses according to the characteristics of their local universities and reduce the learning costs required for e-learning and the time needed to adopt e-learning platforms. This in turn would improve the teaching effect of online learning, and therefore increase student dependence on it. When students' acceptance of online courses increases and generates satisfaction, their behavior and identification with the new habit of using online learning are enhanced. This improves their habits of using online learning and thereby increases their switching intention for online learning.
From a theoretical perspective, previous switching behavior studies on PPM have tended to discuss long-termoriented migration behavior, such as switches from Instagram to Facebook (Hou \& Shiau, 2020), from E-commerce to M-Shopping or social commerce (Chang et al., 2017; Li $\& \mathrm{Ku}, 2018$ ), or from mobile instant messaging (Sun et al., 2017) or cloud storage services (Cheng et al., 2019; Wu et al., 2017). This study investigated migration behavior during the emergency management implemented by Chinese universities under the impact of COVID-19 pandemic. Based on the results of this study, different interpretation concepts-for migration behavior under emergency management-are also provided. Second, in the online learning environment, the concept of TTF has not been incorporated into the framework of PPM. This study considered the online environment from the perspective of emergency management of COVID-19 pandemic, and the results differed from the framework model of the user application of technologies discussed in previous studies (e.g., UTAUT, TRA, TPB, TAM; Isaac et al., 2019; Khan et al., 2018; Wu $\&$ Chen, 2017). Previous studies have emphasized the need to consider the appropriateness of TTF in population migration. Thus, the application and integration of PPM and TTF covers a new perspective and enriches the literature on switching behaviors. Third, this study explored the environment for the switch from offline to online learning. Through evaluation, TTF, instructor attitude, perceived usefulness, and perceived ease of use were regarded as two-level concepts that formed push effects. However, switching behavior-related literature has not investigated the concept of instructor attitude as an influencing push effect and has focused mostly on aspects of student learning (Balakrishnan et al., 2017; Liao et al., 2019). Discussing instructor attitude can further explain the effect of teaching interaction on understanding switching intention in the online teaching environment.

\section{Limitations and Future Research}

In general, investigating whether a large-scale educational change can form normal behavior. It is necessary to consider the balance of push, pull, and mooring factors at the same time, especially in the intention to change the mode of human behavior. Omitting one of these factors will bias the entire changed pattern. In the future, this kind of discussion can also be applied to people's lives, employment, schooling, and policy promotion. Unlike a single factor, the push-pull-mooring model method discussed in this study can fully explain the difference in the implementation effects.

There are still some limitations and follow-up questions that need to be determined in the future. Particularly, the 
sample attributes did not cover universities in all provinces of China, which can be addressed in subsequent studies. Regional characteristics that affect the promotion of online learning and student switching intention during the pandemic is also a question of whether it is worth investigating. Second, the sampling in this study was based on the survey approach. Therefore, future studies can focus on qualitative research, which can reveal core factors related to switching intention and produce results that can more effectively explain the quantitative research findings. Finally, to avoid the influence on the statistical results caused by the differences in the sample obtainment, control variables were used to verify the results in this study, and the results showed no significant difference. However, in this study, sample students are limited to only specific majors or genders, so the sampling nature. Sampling reliability may become a research limitation.

Funding This research was funded by K.C. Wong Magna Fund in Ningbo University (RC190015), Ningbo Education Science Planning (2020YQZX173), the provincial "Qinyuan" innovation and entrepreneurship comprehensive experimental teaching center key construction project of the 13th five-year plan of Zhejiang Province (Zhejiang Education Office, ref: [2019]218). This study was supported by the Ministry of Science and Technology, Taiwan, R.O.C., under grant MOST 109-2511-H-019-004-MY2 and MOST 1092511-H-019-001.

\section{Declarations}

Conflict of interest The authors declare that they have no conflict of interest.

Ethical approval Ethical review and approval was not required for the study on human participants in accordance with the local legislation and institutional requirements. The experimental data they provided was anonymous and would not be of any commercial use. All the respondents agreed to participate in the study.

Consent to participate The respondents in the research should realize that they are willing to participate in this study. The respondents fill in the questionnaire as volunteers. All the respondents are anonymous and agree to accept the survey of this study to collect data.

\section{References}

Aagja, J. P., Mammen, T., \& Saraswat, A. (2011). Validating service convenience scale and profiling customers: A study in the Indian retail context. Vikalpa, 36(4), 25-50.

Al-Fraihat, D., Joy, M., \& Sinclair, J. (2020). Evaluating E-learning systems success: An empirical study. Computers in Human Behavior, 102, 67-86

Ashrafi, A., Zareravasan, A., Rabiee Savoji, S., \& Amani, M. (2020). Exploring factors influencing students' continuance intention to use the learning management system (LMS): a multi-perspective framework. Interactive Learning Environments. https://doi.org/10.1080/10494820.2020.1734028
Balakrishnan, V., Teoh, K. K., Pourshafie, T., \& Liew, T. K. (2017). Social media and their use in learning: A comparative analysis between Australia and Malaysia from the learners' perspectives. Australasian Journal of Educational Technology. https://doi.org/10.14742/ajet.2469

Bansal, H. S., Taylor, S. F., \& St. James, Y. (2005). "Migrating” to new service providers: Toward a unifying framework of consumers' switching behaviors. Journal of the Academy of Marketing Science, 33(1), 96-115

Bhattacherjee, A., \& Park, S. C. (2014). Why end-users move to the cloud: a migration-theoretic analysis. European Journal of Information Systems, 23(3), 357-372.

Becker, J. M., Klein, K., \& Wetzels, M. (2012). Hierarchical latent variable models in PLS-SEM: guidelines for using reflectiveformative type models. Long range planning, 45(5-6), 359-394

Berry, L. L., Seiders, K., \& Grewal, D. (2002). Understanding service convenience. Journal of Marketing, 66(3), 1-17

Bogue, D. (1959). Internal migration. In P.N. Hauser \& D. Duncan (Eds.), The Study of Population.

Boyle, P., \& Halfacree, K. (1998). Migration into rural areas: theories and issues. Wiley.

Carter, L., \& Campbell, R. (2012). Internet voting usefulness: An empirical analysis of trust, convenience and accessibility. Journal of Organizational and End User Computing (JOEUC), 24(3), 1-17

Chang, I. C., Liu, C. C., \& Chen, K. (2014). The push, pull and mooring effects in virtual migration for social networking sites. Information Systems Journal, 24(4), 323-346

Chang, H. H., Wong, K. H., \& Li, S. Y. (2017). Applying push-pullmooring to investigate channel switching behaviors: M-shopping self-efficacy and switching costs as moderators. Electronic Commerce Research and Applications, 24, 50-67

Chen, Y. H., \& Keng, C. J. (2019). Utilizing the Push-Pull-MooringHabit framework to explore users' intention to switch from offline to online real-person English learning platform. Internet Research. https://doi.org/10.1108/IntR-09-2017-0343

Chen, C. D., Zhao, Q., \& Wang, J. L. (2020). How livestreaming increases product sales: role of trust transfer and elaboration likelihood model. Behaviour \& Information Technology. https://doi.org/10.1080/0144929X.2020.1827457

Cheng, X. (2020). Challenges of "School's Out, But Class's On" to School Education: Practical Exploration of Chinese Schools during the COVID-19 Pandemic. Science Insights Education Frontiers, 5(2), 501-516

Cheng, S., Lee, S. J., \& Choi, B. (2019). An empirical investigation of users' voluntary switching intention for mobile personal cloud storage services based on the push-pull-mooring framework. Computers in Human Behavior, 92, 198-215

Cidral, W. A., Oliveira, T., Di Felice, M., \& Aparicio, M. (2018). E-learning success determinants: Brazilian empirical study. Computers and Education, 122, 273-290

Dai, H. M., Teo, T., Rappa, N. A., \& Huang, F. (2020). Explaining Chinese university students' continuance learning intention in the MOOC setting: A modified expectation confirmation model perspective. Computers and Education, 150, 103850

Dijkstra, T. K., \& Henseler, J. (2015). Consistent partial least squares path modeling. MIS quarterly, 39(2), 297-316

Eksail, F. A. A., \& Afari, E. (2019). Factors affecting trainee teachers' intention to use technology: A structural equation modeling approach. Education and Information Technologies. https://doi.org/10.1007/s10639-019-10086-2

Fatima, A., Sunguh, K. K., Abbas, A., Mannan, A., \& Hosseini, S. (2020). Impact of pressure, self-efficacy, and self-competency on students' plagiarism in higher education. Accountability in Research, 27(1), 32-48. https://doi.org/10.1080/08989621.2019.1699070 
Fornell, C., \& Larcker, D. F. (1981). Evaluating structural equation models with unobservable variables and measurement error. Journal of marketing research, 18(1), 39-50

Gefen, D., Karahanna, E., \& Straub, D. W. (2003). Trust and TAM in online shopping: An integrated model. MIS Quarterly, 27(1), $51-90$

Gefen, D., Rigdon, E. E., \& Straub, D. (2011). Editor's comments: an update and extension to SEM guidelines for administrative and social science research. MIS Quarterly, 35(2), iii-xiv

Grewal, D., Munger, J. L., Iyer, G. R., \& Levy, M. (2003). The influence of internet-retailing factors on price expectations. Psychology and Marketing, 20(6), 477-493

Hair, J. F., Black, W. C., Babin, B. J., Anderson, R. E., \& Tatham, R. L. (2006). Multivariate data analysis. (6th ed.). Pearson Prentice Hall.

Hair, J. F., Jr., Babin, B. J., \& Krey, N. (2017a). Covariance-based structural equation modeling in the Journal of Advertising: Review and recommendations. Journal of Advertising, 46(1), 163-177

Hair, J., Hollingsworth, C. L., Randolph, A. B., \& Chong, A. Y. L. (2017b). An updated and expanded assessment of PLS-SEM in information systems research. Industrial Management and Data Systems, 117(3), 442-458

Hou, A. C., \& Shiau, W. L. (2020). Understanding Facebook to Instagram migration: a push-pull migration model perspective. Information Technology and People, 33(1), 272-295

Hsieh, J. K., Hsieh, Y. C., Chiu, H. C., \& Feng, Y. C. (2012). Postadoption switching behavior for online service substitutes: A perspective of the push-pull-mooring framework. Computers in Human Behavior, 28(5), 1912-1920

Hsu, J. Y., Chen, C. C., \& Ting, P. F. (2018). Understanding MOOC continuance: An empirical examination of social support theory. Interactive Learning Environments, 26(8), 1100-1118

Huang, L. C., \& Shiau, W. L. (2017). Factors affecting creativity in information system development. Industrial Management and Data Systems, 117(3), 496-520

Huang, F., \& Teo, T. (2019). Influence of teacher-perceived organizational culture and school policy on Chinese teachers' intention to use technology: an extension of technology acceptance model. Educational Technology Research and Development, 68, 1547-1567

Huang, F., Teo, T., \& Zhou, M. (2020). Chinese students' intentions to use the Internet-based technology for learning. Educational Technology Research and Development, 68(1), 575-591

Isaac, O., Aldholay, A., Abdullah, Z., \& Ramayah, T. (2019). Online learning usage within Yemeni higher education: The role of compatibility and task-technology fit as mediating variables in the IS success model. Computers and Education, 136, 113-129

Jung, J., Han, H., \& Oh, M. (2017). Travelers' switching behavior in the airline industry from the perspective of the push-pullmooring framework. Tourism Management, 59, 139-153

Khan, I. U., Hameed, Z., Yu, Y., Islam, T., Sheikh, Z., \& Khan, S. U. (2018). Predicting the acceptance of MOOCs in a developing country: Application of task-technology fit model, social motivation, and self-determination theory. Telematics and Informatics, 35(4), 964-978

Kim, H. W., \& Kankanhalli, A. (2009). Investigating user resistance to information systems implementation: A status quo bias perspective. MIS Quarterly, 33(3), 567-582

Kim, D. J., Ferrin, D. L., \& Rao, H. R. (2008). A trust-based consumer decision-making model in electronic commerce: The role of trust, perceived risk, and their antecedents. Decision Support Systems, 44(2), 544-564

Lai, J. Y., \& Wang, J. (2015). Switching attitudes of taiwanese middle-aged and elderly patients toward cloud healthcare services: An exploratory study. Technological Forecasting and Social Change, 92, 155-167.

Lin, C. L., Yu, S. W., Su, Y. S., Fu, F. L., \& Lin, Y. T. (2019). Charismatic learning: Students' satisfaction with e-learning in higher education. Journal of Internet Technology, 20(5), $1665-1672$.

Kissi, P. S., Nat, M., \& Armah, R. B. (2018). The effects of learningfamily conflict, perceived control over time and task-fit technology factors on urban-rural high school students' acceptance of video-based instruction in flipped learning approach. Educational Technology Research and Development, 66(6), 1547-1569

Kuo, Y. F., Hu, T. L., \& Yang, S. C. (2013). Effects of inertia and satisfaction in female online shoppers on repeat-purchase intention. Managing Service Quality: An International Journal., 23(3), 168-187

Ladhari, R. (2009). Service quality, emotional satisfaction, and behavioural intentions. Managing Service Quality: An International Journal, 19(3), 308-331

Lai, J. Y., Debbarma, S., \& Ulhas, K. R. (2012). An empirical study of consumer switching behaviour towards mobile shopping: a Push-Pull-Mooring model. International Journal of Mobile Communications, 10(4), 386-404

Lee, E. S. (1966). A theory of migration. Demography, 3(1), 47-57

Li, C. Y. (2018). Consumer behavior in switching between membership cards and mobile applications: The case of Starbucks. Computers in Human Behavior, 84, 171-184.

Li, C. Y., \& Ku, Y. C. (2018). The power of a thumbs-up: Will e-commerce switch to social commerce? Information and Management, 55(3), 340-357

Liao, Y. W., Huang, Y. M., Huang, S. H., Chen, H. C., \& Wei, C. W. (2019). Exploring the Switching Intention of Learners on Social Network-based Learning Platforms: A Perspective of the PushPull-Mooring Model. EURASIA Journal of Mathematics, Science and Technology Education, 15(9), 1-10

Lin, T. C., \& Huang, S. L. (2014). Understanding the determinants of consumers' switching intentions in a standards war. International Journal of Electronic Commerce, 19(1), 163-189

Lin, W. S., \& Wang, C. H. (2012). Antecedences to continued intentions of adopting e-learning system in blended learning instruction: A contingency framework based on models of information system success and task-technology fit. Computers and Education, 58(1), 88-99

Lindell, M. K., \& Whitney, D. J. (2001). Accounting for common method variance in cross-sectional research designs. Journal of applied psychology, 86(1), 114-121

Mangin, J. P. M. L., Guerrero, M. M., Bourgault, N., \& Egea, J. M. O. (2013). Exploring the influence of price and convenience on perceived usefulness of on-line banking within the TAM framework: A cross national (Canada and Spain) decision model. Journal of Business Theory and Practice, 1(2), 342-362

Maslach, C., Jackson, S. E., Leiter, M. P., Schaufeli, W. B., \& Schwab, R. L. (1986). Maslach burnout inventory. (Vol. 21, pp. 3463-3464). Consulting psychologists press.

Ministry of Education of the People's Repub-lic of China. (2020) "Notice on 'School's Out, But Class's On' Work Arrangements during the Postponed Period", 2020-02-12, http: // www.moe.gov.cn.

Ministry of Education of the People's Republic of China. 2020a. Guidance on the Organization and Management of Online Teaching in Colleges and Universities during the Epidemic Prevention and Control Period. Available online: http://www.moe.gov.cn/srcsite/A08/s7056/202002/ t20200205_418138.html (accessed on 27 Feb 2021). 
Mohammadi, H. (2015). Investigating users' perspectives on e-learning: An integration of TAM and IS success model. Computers in human behavior, 45, 359-374

Mokkink, L. B., Terwee, C. B., Patrick, D. L., Alonso, J., Stratford, P. W., Knol, D. L., \& De Vet, H. C. (2010). The COSMIN checklist for assessing the methodological quality of studies on measurement properties of health status measurement instruments: an international Delphi study. Quality of life research, 19(4), 539-549

Moon, B. (1995). Paradigms in migration research: exploring 'moorings' as a schema. Progress in human geography, 19(4), $504-524$

Michaelidou, N., \& Christodoulides, G. (2011). Antecedents of attitude and intention towards counterfeit symbolic and experiential products. Journal ofMarketing Management, 27(9-10), 976-991.

Nicolaou, A. I., \& McKnight, D. H. (2006). Perceived information quality in data exchanges: Effects on risk, trust, and intention to use. Information systemsresearch, 17(4), 332-351.

Petter, S., Straub, D., \& Rai, A. (2007). Specifying formative constructs in information systems research. MIS Quarterly, 31(4), 623-656

Polites, G. L., \& Karahanna, E. (2012). Shackled to the status quo: The inhibiting effects of incumbent system habit, switching costs, and inertia on new system acceptance. MIS quarterly, 36, $21-42$

Rodríguez-Ardura, I., \& Meseguer-Artola, A. (2016). What leads people to keep on e-learning? An empirical analysis of users' experiences and their effects on continuance intention. Interactive Learning Environments, 24(6), 1030-1053

Shiau, W. L., \& Chau, P. Y. (2016). Understanding behavioral intention to use a cloud computing classroom: A multiple model comparison approach. Information and Management, 53(3), 355-365

Shiau, W. L., Sarstedt, M., \& Hair, J. F. (2019). Internet research using partial least squares structural equation modeling (PLSSEM). Internet Research, 29(3), 398-406

Shiau, W. L., Yuan, Y., Pu, X., Ray, S., \& Chen, C. C. (2020). Understanding fintech continuance: perspectives from selfefficacy and ECT-IS theories. Industrial Management and Data Systems., 120, 1659-1689

Shiau, W. L., Yuan, Y., Pu, X., Ray, S., \& Chen, C. C. (2020a). Understanding fintech continuance: perspectives from selfefficacy and ECT-IS theories. Industrial Management and Data Systems, 120(9), 1659-1689

Shih, W. C., Tseng, S. S., \& Yang, C. T. (2008). Wiki-based rapid prototyping for teaching-material design in e-Learning grids. Computers and Education, 51(3), 1037-1057

Smith, G. G., \& Ferguson, D. (2004). Diagrams and math notation in e-learning: growing pains of a new generation. International Journal of Mathematical Education in Science and Technology, 35(5), 681-695

Stimson, R. J., \& Minnery, J. (1998). Why people move to the'sunbelt': A case study of long-distance migration to the gold coast, australia. UrbanStudies, 35(2), 193-214.

Straub, D., Boudreau, M. C., \& Gefen, D. (2004). Validation guidelines for IS positivist research. Communications of the Association for Information systems, 13(1), 380-427

Su, Y. S., \& Chen, H. R. (2020). Social Facebook with big six approaches for improved students' learning performance and behavior: A case study of a project innovation and implementation course. Frontiers in Psychology, 11, 1166

Su, Y. S., Lin, C. L., Chen, S. Y., \& Lai, C. F. (2019a). Bibliometric study of social network analysis literature. Library Hi Tech, 38, $420-433$
Su, Y. S., Chou, C. H., Chu, Y. L., \& Yang, Z. F. (2019b). A fingerWorn device for exploring chinese printed text with using CNN algorithm on a micro IoTprocessor. IEEE, 7, 116529-116541.

Su, Y. S., Ni, C. F., Li, W. C., Lee, I. H., \& Lin, C. P. (2020). Applying deep learning algorithms to enhance simulations of large-scale groundwater flow inIoTs. Applied Soft Computing, 92, 10629

Su, Y. S., \& Wu, S. Y. (2020). Applying data mining techniques to explore users behaviors and viewing video patterns in converged IT environments. Journal of Ambient Intelligence and Humanized Computing. https://doi.org/10.1007/s12652-020-02712-6.

Su, Y. S., Ding, T. J., \& Chen, M. Y. (2021a). Deep learning methods in internet of medical things for valvular heart disease screening system. IEEE Internet of Things Journal. https://doi.org/10.1109/JIOT.2021.3053420.

Su, Y. S., Suen, H. Y., \& Hung, K. E. (2021b). Predicting behavioral competencies automatically from facial expressions in real-time video recorded interviews. Journal of Real-Time ImageProcessing. https://doi.org/10.1007/s11554-021-01071-5.

Sun, P. C., Tsai, R. J., Finger, G., Chen, Y. Y., \& Yeh, D. (2008). What drives a successful e-Learning? An empirical investigation of the critical factors influencing learner satisfaction. Computers and education, 50(4), 1183-1202

Sun, Y., Liu, D., Chen, S., Wu, X., Shen, X. L., \& Zhang, X. (2017). Understanding users' switching behavior of mobile instant messaging applications: An empirical study from the perspective of push-pull-mooring framework. Computers in Human Behavior, 75, 727-738

Susanty, A., Handoko, A., \& Puspitasari, N. B. (2020). Push-pullmooring framework for e-commerce adoption in small and medium enterprises. Journal of Enterprise Information Management, 33(2), 381-406

Tang, Z., \& Chen, L. (2020). An empirical study of brand microblog users' unfollowing motivations: The perspective of push-pullmooring model. International Journal of Information Management, 52, 102066

UNESCO. (2020). School closures caused by Coronavirus (Covid19). https://en.unesco.org/covid19/educationresponse

Wang, Y., \& Haggerty, N. (2011). Individual virtual competence and its influence on work outcomes. Journal of Management Information Systems, 27(4), 299-334

Wang, K., Lin, C. L., Chen, C. D., and Yang, S. C. (2008). The adoption of wikipedia: A community-and information qualitybased view. PACIS 2008 Proceedings, 50.

Wang, L., Luo, X. R., Yang, X., \& Qiao, Z. (2019). Easy come or easy go? Empirical evidence on switching behaviors in mobile payment applications. Information and Management, 56(7), 103150

Wu, B., \& Chen, X. (2017). Continuance intention to use MOOCs: Integrating the technology acceptance model (TAM) and task technology fit (TTF) model. Computers in Human Behavior, 67, 221-232

Wu, L., Cai, Y., \& Liu, D. (2011). Online shopping among Chinese consumers: An exploratory investigation of demographics and value orientation. International journal of consumer studies, 35(4), 458-469

Wu, K., Vassileva, J., \& Zhao, Y. (2017). Understanding users' intention to switch personal cloud storage services: Evidence from the Chinese market. Computers in Human Behavior, 68, 300-314

Wang, K., \& Lin, C. L. (2012). The adoption of mobile valueadded services. Managing ServiceQuality: An International Journal,. 22, 184-208. https://doi.org/10.1108/09604521211219007

Xu, Y. C., Yang, Y., Cheng, Z., \& Lim, J. (2014). Retaining and attracting users in social networking services: An empirical 
investigation of cyber migration. The Journal of Strategic Information Systems, 23(3), 239-253

Yao, J., Rao, J., Jiang, T., \& Xiong, C. (2020). What Role Should Teachers Play in Online Teaching during the COVID-19 Pandemic? Evidence from China. Sci Insigt Edu Front, 5(2), $517-524$

Yu, T. K., \& Yu, T. Y. (2010). Modelling the factors that affect individuals' utilisation of online learning systems: An empirical study combining the task technology fit model with the theory of planned behaviour. British Journal of Educational Technology, 41(6), 1003-1017

Zhang, K. Z., Cheung, C. M., \& Lee, M. K. (2012). Online service switching behavior: The case of blog service providers. Journal of Electronic Commerce Research, 13(3), 184
Zhang, L., Shao, Z., Pan, Z., \& Feng, Y. (2019). Examining Individuals' Utilization of SPOC: Extending the Task-Technology Fit Model with Online and Offline Perspective. (p. 202). PACIS.

Zhang, W., Wang, Y., Yang, L., \& Wang, C. (2020). Suspending classes without stopping learning: China's education emergency management policy in the COVID-19 Outbreak. Journal of Risk and Financial Management, 13(3), 55-60

Publisher's Note Springer Nature remains neutral with regard to jurisdictional claims in published maps and institutional affiliations. 